\title{
The effectiveness of fault detection in common rail injectors examination methods
}

The article presents the effectiveness tests of fault detection in common rail injectors. 40 injectors with different wear levels were tested. Testing was made on two test benches of a completely different design. Research includes comparison of accuracy, reproducibility and testability to detect specific defects. A device was created for visualization of the fuel injector spraying steam.

Key words: injector testing, common rail, injector test stand, measurement methods, injection spray pattern

\section{Introduction}

The aim of the following article is to evaluate the workshop methods of testing injectors used in modern compression ignition engines. Various test benches and devices for fuel atomization process visualization were used to evaluate the effectiveness of the damage detection. Not only injectors are evaluated in terms of fuel dosage but also in the shape of the stream or atomization of droplets. A widely used automatic test in 4 operating points may lead to confusion when deciding about the reconditioning of the injector. The examinations expanded with injector characteristics in a wide range of parameter changes coupled with experience of machine operator leads to more precise diagnostics and can even indicate malfunction of other engine components or improper engine maintenance.

\section{Injector testers}

Test bench is a device designed for, among others, injector examination. It provides conditions necessary for injector to work and allows its working properties measurement. Test Benches are used in injector repair workshops in several stages of injector reconditioning process such as:

- Introductory examination of injector in purpose of defect verification

- Regulation of injector

- Check operation after repair

- IMA code assignment

Injector testers are also useful in car workshops. In many cases it is impossible to set a clear engine diagnosis. Testing benches are tools that help to determine, whether the defect is caused by injectors and which one exactly. Another application of test benches are science researches and development works.

In purpose of testing of injectors, instead of using diesel oil, required calibration fluid is used. Its properties are precisely determined by ISO 4113 standard or other standards created by producers on a basis of ISO 4113 .

The injected fuel quantity, and the return quantity are basic quantities measured by the test benches. The most common method of testing injectors is measuring the injector parameters in 4 operating points. The first operating point is a full load dosage, which simulates work of the injector during engine's full load. The second parameter is an emission dosage, which corresponds to the medium load of the engine. The next measured dose is an idle dose (LL). The last measured dose is a pre injection dose. The manufacturer of injectors determines conditions for those tests, like fuel pressure and actuation time. The ranges of correct dosage values are also provided. This kind of test is relatively fast and allows to diagnose most of injector's malfunctions. However, the diagnose of some of the malfunctions is impossible, since in the real operation injectors work in the whole range of pressures and actuation times. More precise method is to determine the characteristics of injector working with many operating points. In this case, a problem with interpretation of the results appears, because manufacturer does not share characteristics of injectors in working order. Moreover, such measurement may even take couple of hours, so it's problematic in case of workshop use. The additional test, carried out as the first one, is the leak test. It is carried out with maximum operating pressure and without actuation. This test enables to check the nozzle and control valve tightness. Leaks flowing through fuel return port are measured automatically, while other leaks, especially the nozzle leak, are supposed to be checked visually by the machine operator.

Two test benches were used in order to carry out this research. The first one is STPiW 3. It is available in the laboratory of Gdańsk University Of Technology. The second device is Bosch EPS 200, provided through courtesy of Motogab injectors reconditioning workshop. These machines differ when it comes to their research capabilities. The main difference is the method of measurement of a fuel quantity. This measurement in case of Bosh EPS 200 is performed with a turbine flowmeter. The advantage of this device is a real time measurement, which speeds up the time of a test. In case of STPiW 3 fuel quantity is measured indirectly through measurement of hydrostatic pressure of calibration fluid injected to the measuring cylinders.

\subsection{Bosch EPS 200}

The Bosch EPS 200 (Fig. 1) is an automatic injector tester. It has a compact design but allows to test only one injector at a time. It consists of a high pressure pump Bosch $\mathrm{CP} 3$, which pumps the test oil to a rail. The rail is equipped with a piezoelectric pressure sensor and a pressure control valve.

The built-in two-chamber calibration fluid reservoir has a capacity of approximately 7 litres. The fluid used in the test is drained into the first chamber where larger impurities 
are deposited. In the second chamber, the test oil is brought to the correct test temperature and then fed to the high pressure pump. The most important element of the device is the turbine flowmeter, because it directly reflects on the accuracy of measurements.

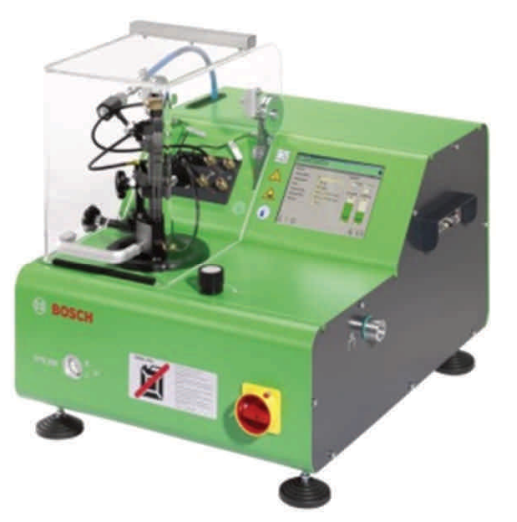

Fig. 1. Bosch EPS 200

The flowmeter measures the injected fuel quantity or the return quantity, depending on the setting of the valves directing the streams flowing out of a tested injector.

Measurements are possible only in an automatic mode, which is controlled according to the test procedure specified for each kind of injector. This makes the workshop test, comfortable and fast, and greatly limits the possibility of human error. On the other hand, in laboratory conditions, it also limits testing capabilities. [2]

In the case of piezo injectors, to ensure their proper operation, it is important to determine the threshold voltage for the piezo actuator. During exploitation, the nature of the piezo stack and the components directly associated with it may be changed and the ISA code designated at the factory may become wrong. The Bosch EPS can check the adequacy of this code and take it into account when the impulses are generated during the test. Furthermore, the construction of the piezo injectors requires increased return back pressure (approximately 10 bar) which EPS provides.

\subsection{STPiW 3}

STPiW 3 is designed for testing pumps, injectors, pressure sensors and control valves which occur in common rail systems and systems with distributor pump. Construction of the test bench allows simultaneous testing of four injectors. Figure 3 shows the layout of the device. The fuel system has all the elements that can be found in a system of a car. The electric feed pump (1) supplies calibration fluid through the filter (2) to the high pressure pump (PO1). This is the 3-plunger radial-piston pump Bosch $\mathrm{CP} 1 \mathrm{H}$. It is driven through toothed belt by the induction motor (SIL). The motor is powered by the inverter (FAL) that provides smooth and precise speed control. The pump is controlled by the cut-off valve (ZAW2) and the pressure regulator valve (ZAW3). The rail $(\mathrm{K})$ is equipped with the pressure sensor (CC1) and the pressure control valve (ZAW1). Pressure value in a high pressure system is controlled by the electronic module (D2) which controls all valves on the basis of a sensor reading. Tested injectors connected by flexible cables are placed in the injected fuel quantity measuring cylinders $(\mathrm{H})$. On the right side, there are cylinders that measure the return quantity (I). All return pipes are connected to the return collector (9) from which the liquid flows into the main tank (4). Injectors control the pulse generator (D1), which is set by the software on the computer connected to the device. In order to maintain accuracy of the tests and comparability of the results, it is necessary to keep the fluid temperature constant. This is done by the system, marked by dotted line, consisting of the heater (6), the electric pump (7) and the cooler with the fan (WEN1).

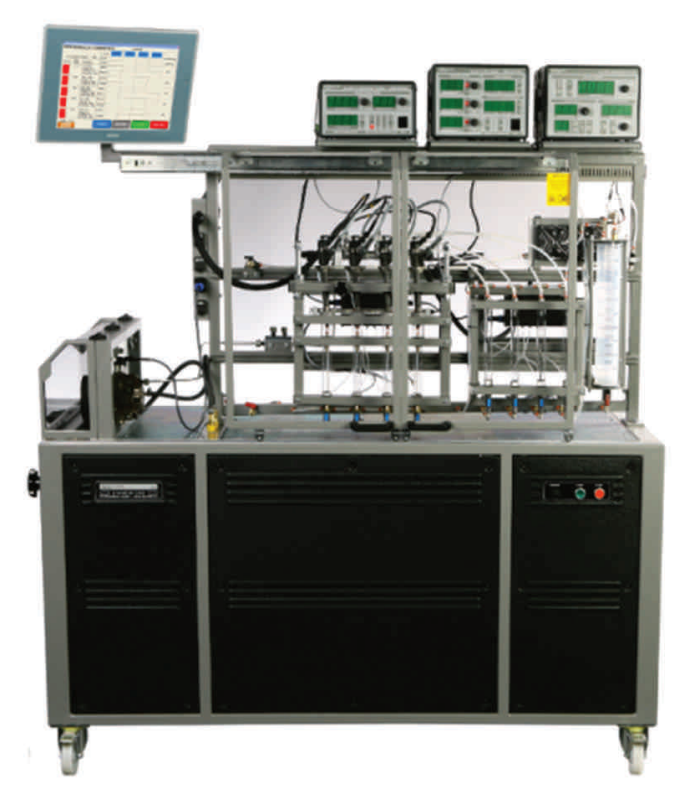

Fig. 2. STPiW 3

Quantity measurement begins with the measurement of hydrostatic pressure of the liquid in the measuring cylinders (H). Subsequently, the motor driving the pump is started. When the pump speed is stabilized, the pressure is adjusted to the setpoint. In the next stage, the injectors starts injecting the calibration fluid into the measuring cylinders. The standard measuring cycle is set to 1000 injections. At the end of the series of injections, the hydrostatic pressure is measured again. Based on the pressure difference, before and after a test, the software calculates the amount of liquid that has increased during the test. Afterwards the volume is divided by the amount of injections which determines the injected fuel quantity.

The great advantage of this device is capability of setting parameters such as:

- fuel pressure,

- actuation time,

- frequency of injections,

- amount of injections,

- pump speed,

- fuel temperature.

This allows to examine the injectors at every point of operation and allows to determine the characteristics according to different parameters. Because of the reasons mentioned above, the STPiW device has bigger testing capabilities and a wider use in research. 


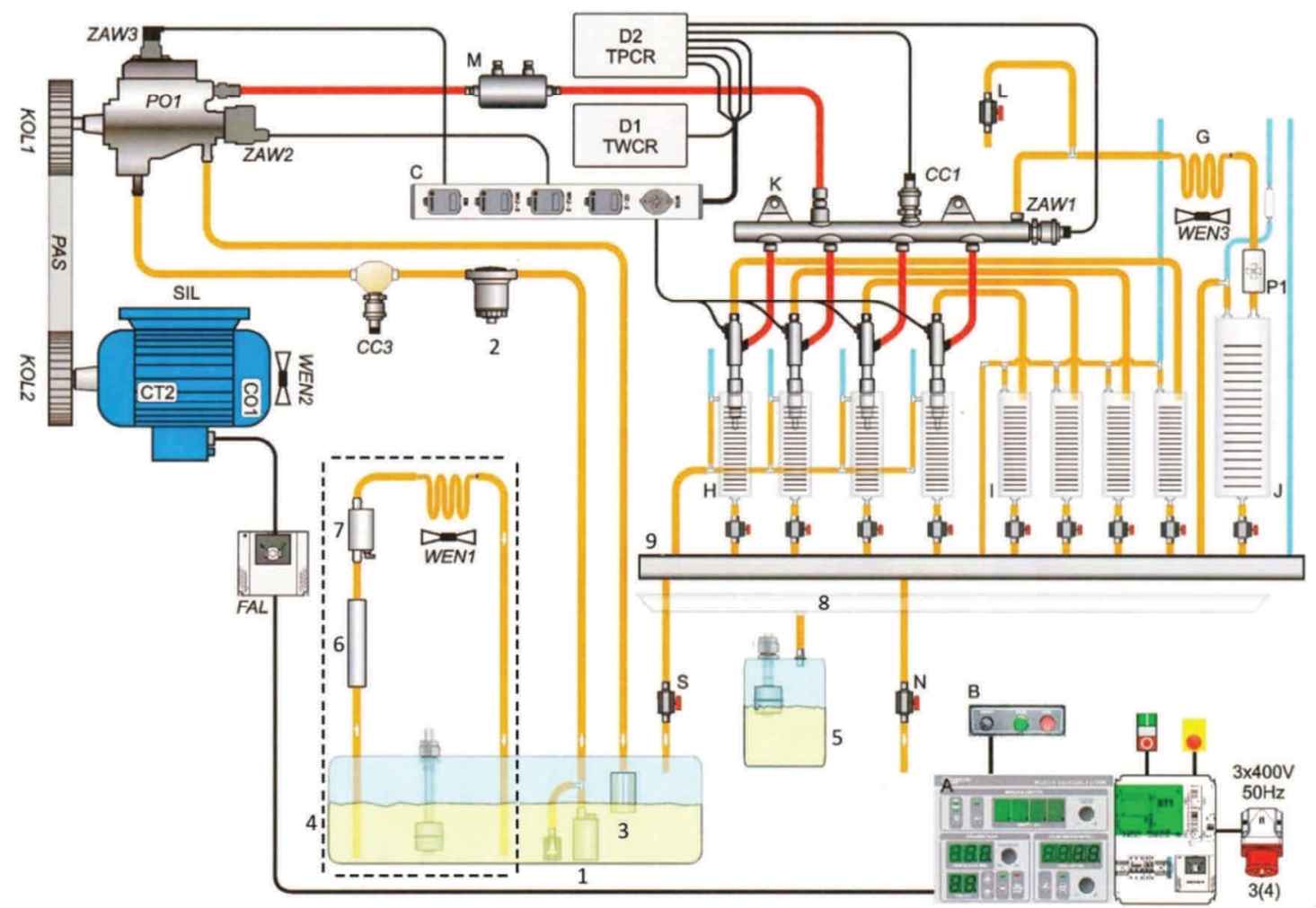

Fig. 3. Scheme of STPiW device

\section{Observed causes of measurement errors}

\subsection{Measurement error of pre injection test}

During examination in automatic mode, according to the injector card, measurement inaccuracy was noticed while performing the VE test. The measurements was carried out with the Bosch injector number 0445110021. Settings, according to the injector card, were as follows:

- Pressure $80 \mathrm{MPa}$,

- Actuation time $160 \mu \mathrm{s}$,

- Number of impulses 1000,

- Frequency $20 \mathrm{~Hz}$

The results of 20 measurements that were performed under the conditions shown above, are presented in the Fig. 4.

Standard deviation was relatively high and amounted: $\sigma=0.266$.

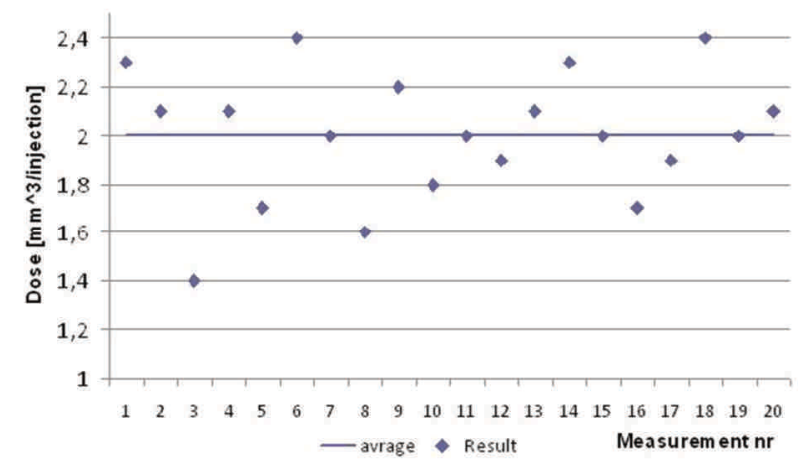

Fig. 4. Outlines of VE test before test modification

During those tests, little amount of fluid (about $2 \mathrm{ml}$ ) was injected to the measuring cylinder in time of one measurement. Precision of the test would be better if the number of impulses in time of one test was increased. Such modification would lead to increase of a measured volume. During consecutive examinations the number of impulses was increased to 4000 . The distribution of results after the test modification is presented in the Fig. 5.

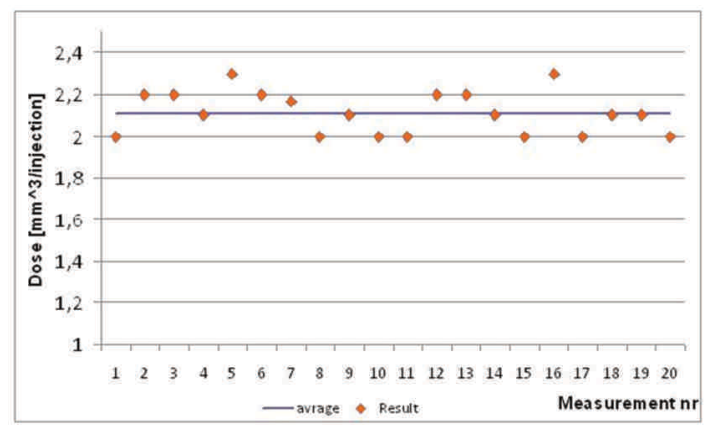

Fig. 5. Outlines of VE test after test modification

In that way the standard deviation decreased more than twice to the value $\sigma=0.103$.

The change of parameters has given expected results, so the following VE measurements was performed with 4000 impulses.

\subsection{Error of the first measurement}

In order to increase accuracy of measurements, every test was repeated several times. It was noticed that the result of the first measurement, which was carried out immediately after setting the injector on the test bench, in many cases was significantly different from the other results in many cases. The first hypothesis to explain this 
phenomenon was an influence of the injector and its components' temperature on injected fuel quantity. It was thought that results stabilized after the injector was heated to the calibration fluid temperature. In order to examine influence of the temperature on the injector operation, the injector was cooled down to the temperature of $5^{\circ} \mathrm{C}$, afterwards it was mounted on a bench. The injected fuel quantity was measured as the components were warming up. The measurement of temperature was carried out with a digital pyrometer in two places. In the upper part, near the fluid supply connector, and in the lower part, near the nozzle nut. The calibration fluid temperature was stabilized at $40^{\circ} \mathrm{C}$. Table 1 shows the measurement outcomes.

Table 1. Influence of the injector's temperature on injected fuel quantity

\begin{tabular}{|l|c|c|c|}
\hline No & temp. top $\left[{ }^{\circ} \mathrm{C}\right]$ & temp. bottom $\left[{ }^{\circ} \mathrm{C}\right]$ & dose $\left[\mathrm{mm}^{3} /\right.$ injection $]$ \\
\hline 1 & 5.5 & 5.5 & 51.2 \\
\hline 2 & 10.2 & 7.5 & 51.4 \\
\hline 3 & 14.8 & 11.1 & 51.3 \\
\hline 4 & 23 & 17.4 & 51.2 \\
\hline 5 & 27.1 & 25.9 & 50.9 \\
\hline 6 & 29.4 & 27.7 & 51.3 \\
\hline 7 & 31.3 & 29.5 & 51.2 \\
\hline 8 & 34.8 & 30.4 & 51.1 \\
\hline 9 & 35.2 & 30.7 & 51.4 \\
\hline
\end{tabular}

As it is presented in the Table 1, the temperature of the injector has no recognizable influence on the fuel quantity and has nothing to do with the error mentioned above.

It was also noticed that if the injector had previously been examined on the test bench, the error of the first measurement did not occur. Due to the fact that the injectors have not been used for a long time, such results could be caused by accumulation of deposits and slight corrosion which reduced the ease of movement of the injector components.

\subsection{Devices comparison}

Main differences between researched devices are presented in the Table 2.

Table 2. Main differences between test benches

\begin{tabular}{|l|l|}
\hline \multicolumn{1}{|c|}{ Bosch EPS } & \multicolumn{1}{c|}{ STPW } \\
\hline $\begin{array}{l}\text { Quantity measurement with } \\
\text { the turbine flow meter }\end{array}$ & $\begin{array}{l}\text { Quantity measurement indirectly through } \\
\text { measurement of hydrostatic pressure of } \\
\text { calibration fluid injected to the } \\
\text { measuring cylinders }\end{array}$ \\
\hline $\begin{array}{l}\text { Automatic measurement } \\
\text { mode only }\end{array}$ & Automatic measurement mode \\
\hline $\begin{array}{l}\text { Abilities to increase return } \\
\text { pressure and to generate } \\
\text { impulses based on IMA code } \\
\text { (piezo injectors) }\end{array}$ & Lack of these abilities \\
\hline $\begin{array}{l}\text { Possibilities to test 1 injector } \\
\text { at a time }\end{array}$ & Possibilities to test 4 injector at a time \\
\hline
\end{tabular}

In order to compare the accuracy and reproducibility of the measurements, a series of 12 measurements was carried out on both devices. The solenoid injector with a catalogue number 0445110021 was used to carry out the tests. The following graphs (Figs 6-9) presents the results of the tests. Green lines indicate results obtained on the Bosch EPS and grey lines stand for the STPiW device. The minimum permissible quantity is marked with a black line, while the red is the maximum. If injector test results are within the range between these lines, the injector retain its correct work parameters.

The first VL result is vitiated by a gross error, which is marked with a red point (Fig. 6). It will not be considered in calculations.

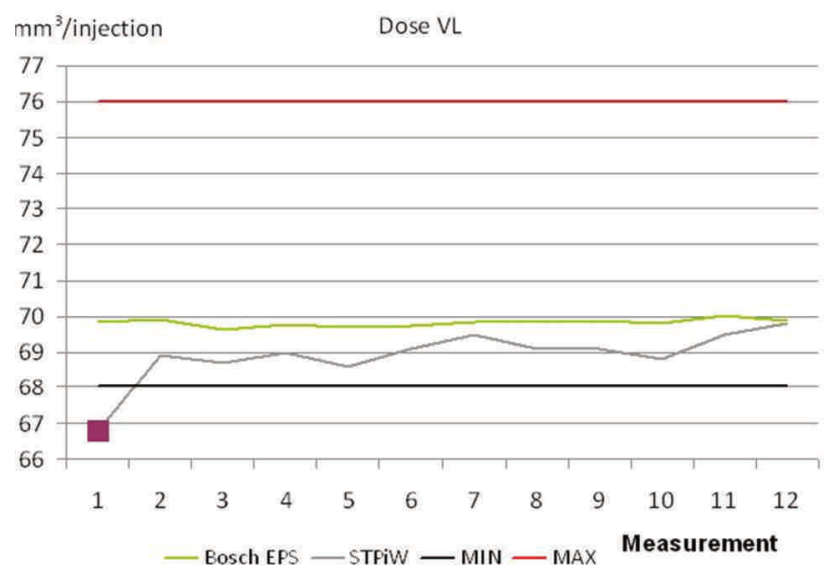

Fig. 6. VL test (actuation time $1300 \mu \mathrm{s}$, pressure $130 \mathrm{MPa}$ )

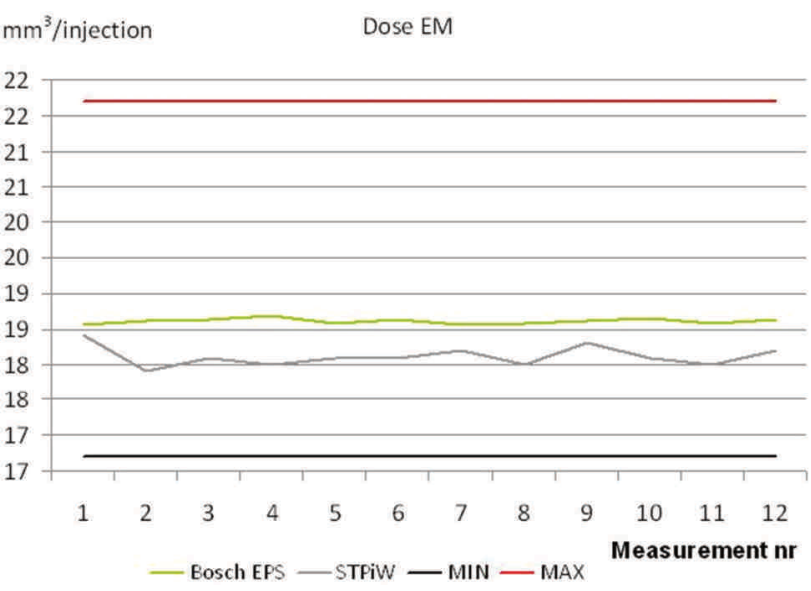

Fig. 7. EM test (actuation time $500 \mu$ s, pressure $80 \mathrm{MPa}$ )

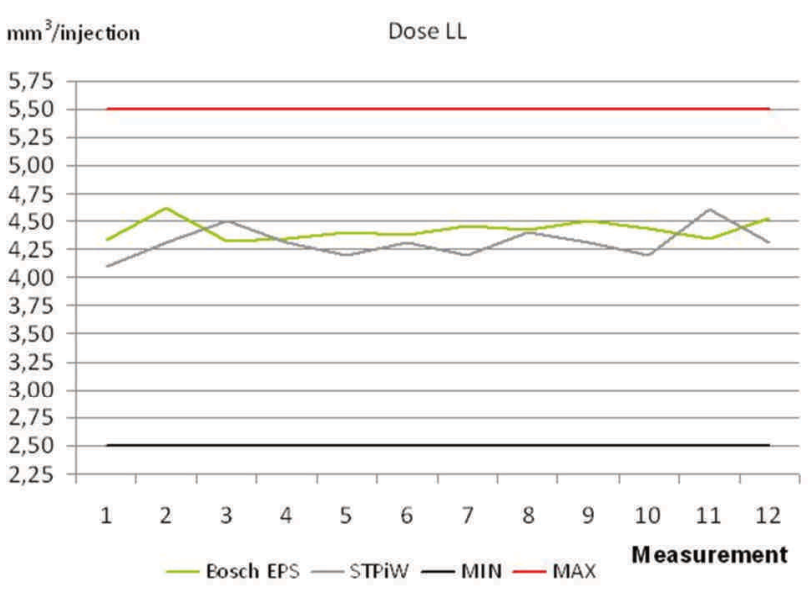

Fig. 8. LL test (actuation time $600 \mu$ s, pressure $25 \mathrm{MPa}$ ) 


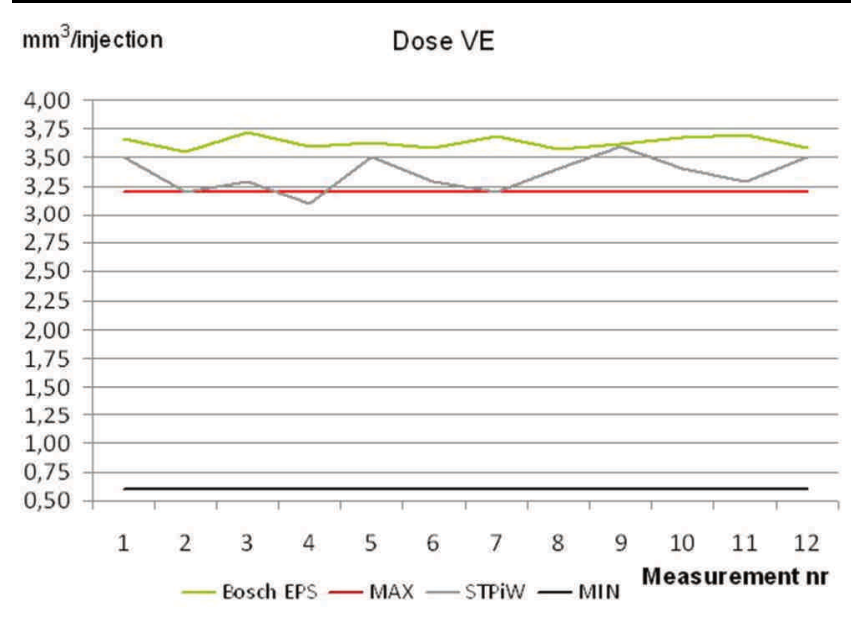

Fig. 9. VE test (actuation time $160 \mu$ s, pressure $80 \mathrm{MPa}$ )

Table 3 shows the juxtaposition of standard deviations of the measurement series depending on the device and the type of test. The arithmetic mean of the standard deviations, which is a measure of the precision, is in the last row of the table. It is very clear that the tests performed with Bosch EPS are more precise and more reproducible. It is also noticed that the standard deviations for the VL tests performed on both devices is much higher than the standard deviations for the other tests. The difference is not due to lower precision of testers in these conditions, but rather to lower precision in the injector dosage at such high pressures and injection times, as the flow process inside the injector is more turbulent.

Table 3. Standard deviations of measurements

\begin{tabular}{|c|c|c|c|}
\hline & & Bosch EPS & STPiW \\
\hline \multirow{4}{*}{ 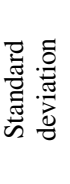 } & VL & 0.1088 & 0.3688 \\
\hline & EM & 0.0386 & 0.1404 \\
\hline & LL & 0.0894 & 0.1380 \\
\hline & VE & 0.0526 & 0.1505 \\
\hline \multicolumn{2}{|c|}{$\begin{array}{c}\text { Average standard } \\
\text { deviation }\end{array}$} & 0.0724 & 0.1994 \\
\hline
\end{tabular}

Table 4 presents the results of average injected fuel quantities. It is clear to see that the results of tests performed by these machines differ insignificantly. In the case of the examined injector, STPiW always indicates slightly lower values. However, considering the other injector's tests, this dependence is not a rule.

Table 4. Average results of measurements

\begin{tabular}{|c|c|c|c|}
\hline & & Bosch EPS & STPiW \\
\hline \multirow{4}{*}{ 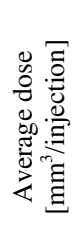 } & VL & 69.82 & 69.10 \\
\hline & EM & 18.61 & 18.12 \\
\hline & LL & 4.42 & 4.31 \\
\hline & VE & 3.63 & 3.36 \\
\hline
\end{tabular}

Return quantity was considered in the case of mentioned comparison. This quantity has no direct influence on the engine's operation, so there is no requirement for the injector dosage to be precise. For this reason, the discrepancies in the measurement results do not reflect the precision of the measuring equipment because they are caused by the nature of the injector work. Therefore, the measurement accuracy of the devices cannot be compared. Fig. 10 presents the distribution of the return quantity measurement results during the VL test.

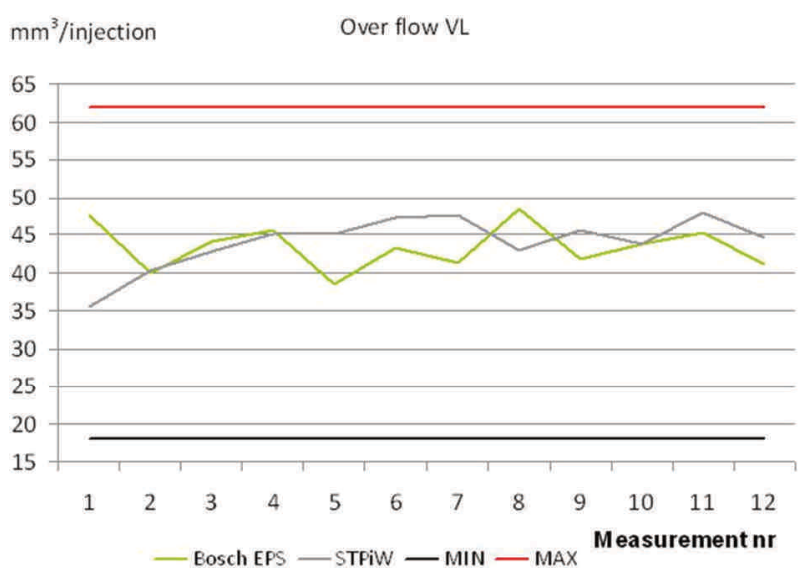

Fig. 10. Return quantity in VL test (actuation time $1300 \mu \mathrm{s}$, pressure $130 \mathrm{MPa})$

\section{Description of the complete injector characteristics interpretation}

The test method at 4 operating points is fast and able to detect most of the faults. However, considering the fact that the injector is operating over the entire span of actuation times and pressures, some defects may remain undetected during the standard test. It often happens after improper injector reconditioning, in which not all of damaged parts have been replaced, and the injector was adjusted just to pass the test. Determining the characteristics in many operating points is much more time-consuming than the standard test.

Full characteristics allows detection of any injector work area where the injector works improperly. On the other hand this measuring method requires testing the injector at multiple operating points leading to a significant prolongation of the test time.

Due to a lack of comparative characteristics, the evaluation of correctness of obtained characteristics consist on checking the parallelism of the sections between two operating points. Owing to the fact that these sections correspond to short time difference, they are treated as straight lines. They should be as parallel to each other as possible. However, in some cases, significant deviations and even intersections are visible, what is unacceptable. The excessive deviations or the line intersection testify to malfunction of the injector.

The test performed on the injector with number 0445 110200 is an example which shows the influence of the complete characteristics interpretation on the injector diagnosis. The injector passed short 4-points test. However, complete characteristics, as shown in Fig. 11, excluded a positive result of injector diagnosis. 
The characteristics clearly illustrate the areas of operation where intersections of the pressure lines occurred. As already mentioned, this is an unacceptable failure.

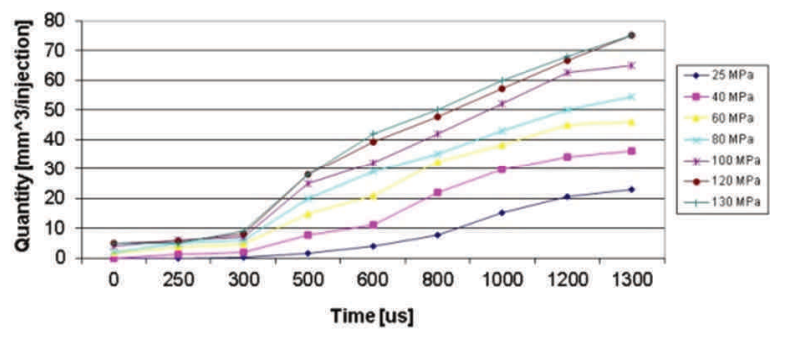

Fig. 11. Characteristic of improper injector work 0445110200

The characteristics above shows that the injector's malfunctions occur especially in the actuation time between 200 and $300 \mu$ s and 450 and $600 \mu s$.

This is proof that the basic test may be insufficient in many cases. In practice, even if the injector completed the first test successfully, an improper working range of the engine could occurred.

Close attention should also be paid to situations in which the characteristics have disturbances especially at high pressures. Due to a leakage of the injector and an excessive return of fuel, the pump is unable to produce high pressure in the fuel rail. Hence the results are falsified (characteristic overlap of high pressure lines corresponding to too low fuel quantities) (Fig. 12). In order to obtain required pressure for the injector, a need to increase the rotational speed of a pump appeared (Fig. 13).

The following characteristics present the situation described above while testing the Denso RF7J 13H50 injectors.

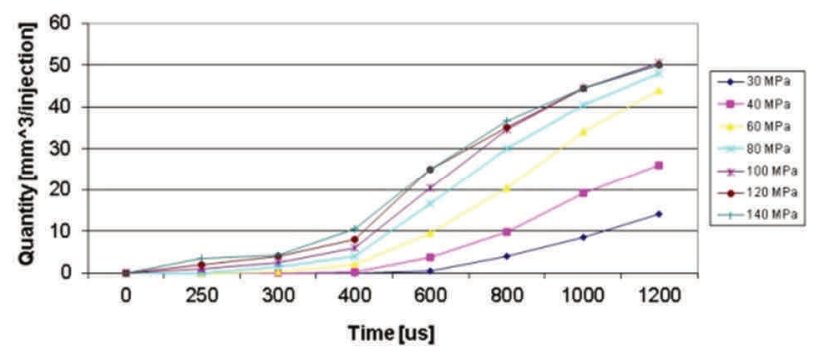

Fig. 12. Characteristic with pump speed $800 \mathrm{rpm}$

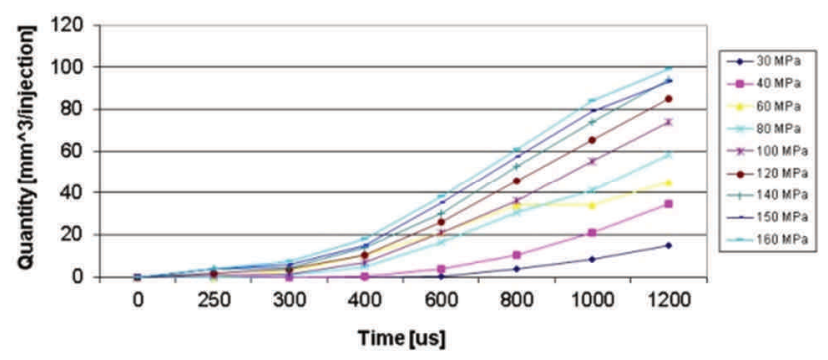

Fig. 13. Characteristic with pump speed $1100 \mathrm{rpm}$

\section{Examination of the Bosch 0445110084 injectors}

The objects of the study in this section are Bosch CRI 1 solenoid injectors with number $0 \quad 445 \quad 110 \quad 084$. The injectors derive from the Renault Laguna with a $2.2 \mathrm{dCi}$ engine. The engine failure occurred at around $220,000 \mathrm{~km}$. The first symptoms of the failure was loss of power, then it was and then impossibility to start the engine.

The examination of the injectors was carried out on the STPiW test bench. The outcomes of the tests are presented in Tab. 5 .

Table 5. Test results of injectors no 0445110084

\begin{tabular}{|c|c|c|c|c|c|c|}
\hline \multirow{4}{*}{\multicolumn{2}{|c|}{ Test }} & \multirow{4}{*}{\begin{tabular}{|c|}
$\begin{array}{c}\text { Injection } \\
\text { time }\end{array}$ \\
$\mu \mathrm{s}$
\end{tabular}} & \multirow{4}{*}{\begin{tabular}{|c|} 
Presure \\
$\mathrm{MPa}$ \\
\end{tabular}} & \multicolumn{3}{|c|}{ Dose $\left[\mathrm{mm}^{3} /\right.$ injection $]$} \\
\hline & & & & \multirow{2}{*}{\multicolumn{2}{|c|}{$\begin{array}{c}\text { Measurement } \\
\text { Injector no }\end{array}$}} & \multirow[t]{3}{*}{ Reqired } \\
\hline & & & & & & \\
\hline & & & & 1 & 2 & \\
\hline \multicolumn{2}{|c|}{ Tightness } & 0 & 140 & 210.7 & 295.2 & $35 \pm 35.0$ \\
\hline \multirow[t]{2}{*}{ VL } & Dose & \multirow{2}{*}{1100} & \multirow{2}{*}{135} & 67 & 71 & $72.1 \pm 4.0$ \\
\hline & Return & & & 167.9 & 182.5 & $40.0 \pm 22.0$ \\
\hline \multicolumn{2}{|l|}{ EM } & 500 & 50 & 13.5 & 13.2 & $8.3 \pm 2.5$ \\
\hline \multicolumn{2}{|l|}{$\mathrm{LL}$} & 500 & 30 & 4.9 & 4.8 & $3.4 \pm 2.0$ \\
\hline \multicolumn{2}{|l|}{ VE } & 260 & 50 & 3.9 & 3.3 & $1.8 \pm 1.3$ \\
\hline \multicolumn{4}{|c|}{ Test result } & Negative & Negative & \\
\hline
\end{tabular}

It can be seen clearly that the injector fault can be already identified during the leak test. The injector number 1 has the return quantity 3 times bigger than the maximum permissible value, while the injector number 2 exceeds that value more than 4 times. This first test may already exclude the injector from further examination because this test is sufficient to determine its fault. Despite this fact, further tests have been carried out in order to observe the effect of leaks on the injected fuel quantity. During a full-load test with a standard pump drive setting at $800 \mathrm{rpm}$, it was not possible to reach a preset pressure of $135 \mathrm{MPa}$ because of too little pump flow in relation to the sum of the injected fuel quantity and the leaks. The pump had been set at 1100 rpm, what increased the pump's output and allowed to maintain the preset pressure.

By analysing the results from tab. 5 , it can be stated that the injector malfunction did not affect the results of full load test. The idle dosage has been slightly increased, but within permissible limits. On the other hand, the emission dosage and the pre-injection dosage were too high.

Inability to start the engine was caused by too big fuel leakage through the injectors, which consequently did not allow the pump rotating with low rotational speed (resulting from the rotational speed of the starter) to build up the pressure in the rail necessary for proper injector activation and engine start-up.

a)

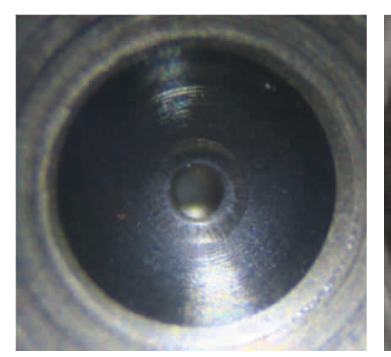

b)

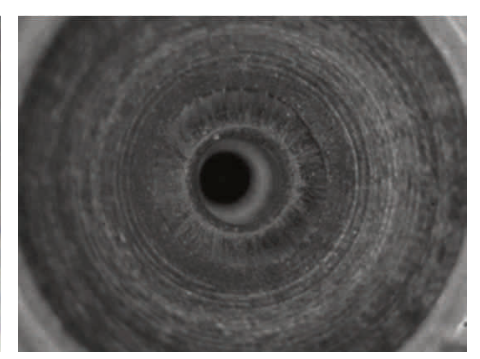

Fig. 14. Damage of the valve seat a) injector no 1, b) injector no 2 


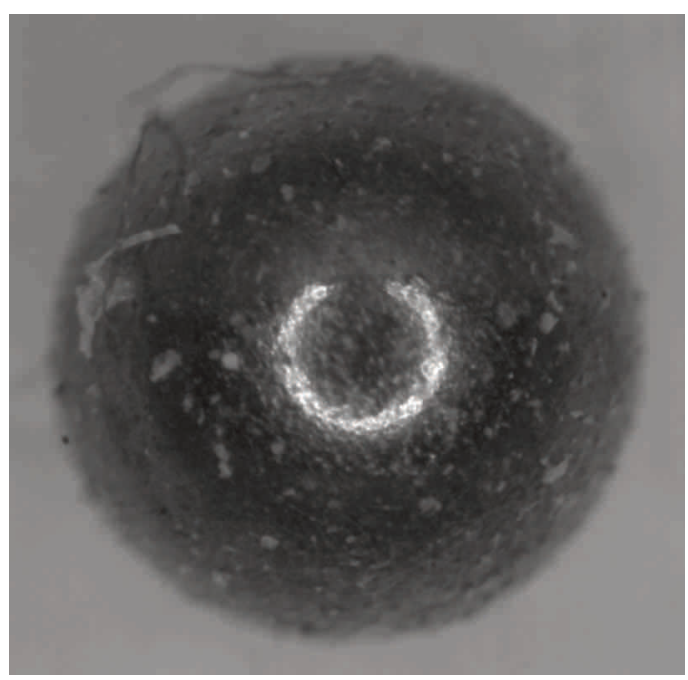

Fig. 15. Damage of the valve ball

Figure 14 presents the control valve seat. The ring around the hole is the sealing surface. The quality of this surface is crucial to maintain valve tightness. The pictures show radial grooves caused by cavitation erosion. In addition, Figure 15 shows the ball of the first injector. The irregularity of the ball's surface is also causes leaks. These are the main causes of the injectors' malfunction the large return quantity.

a)

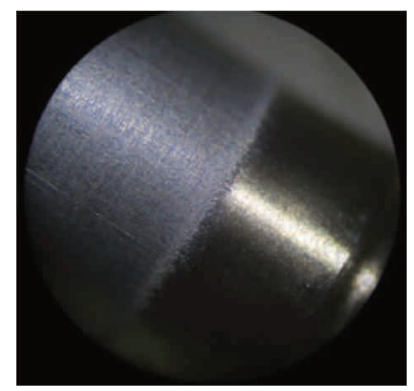

b)

Fig. 16. The guiding surface of needle a) injector no $1, \mathrm{~b}$ ) injector no 2

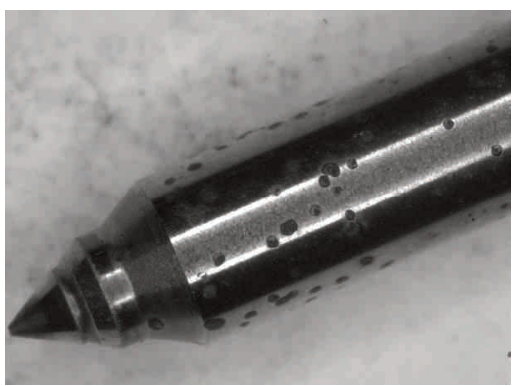

Fig. 17. Needle corrosion

Fig. 16 presents the needles of both injectors, specifically their guiding surfaces. There is a strong abrasive wear at the place where the co-operation with the nozzle occurs and deep dents caused by contamination. These impurities could be caused by corrosion of the needle surface, where pitting spots are visible (Fig. 17). Wear of the cooperation surface resulted in greater clearance of the precision pair such as needle and nozzle. In consequence the clearance caused additional leaks and increased in the return quantity. Analogous wear can be observed in the case of the second precision pair, i.e. the control valve body and the plunger. Fig. 18 shows damage of plungers.
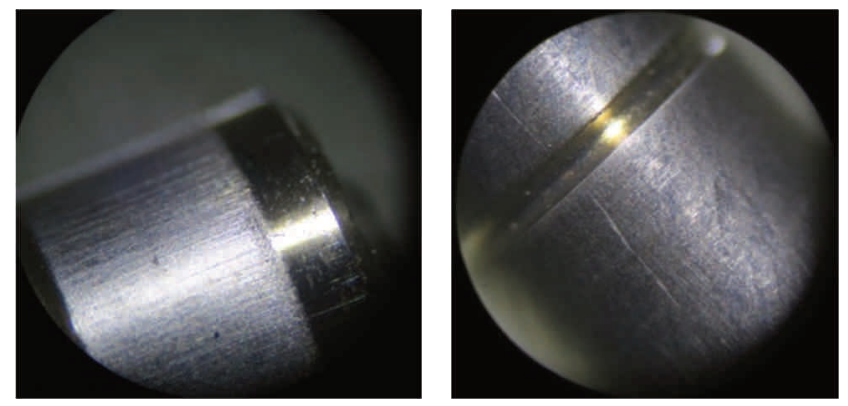

Fig. 18. Damages of valve plungers
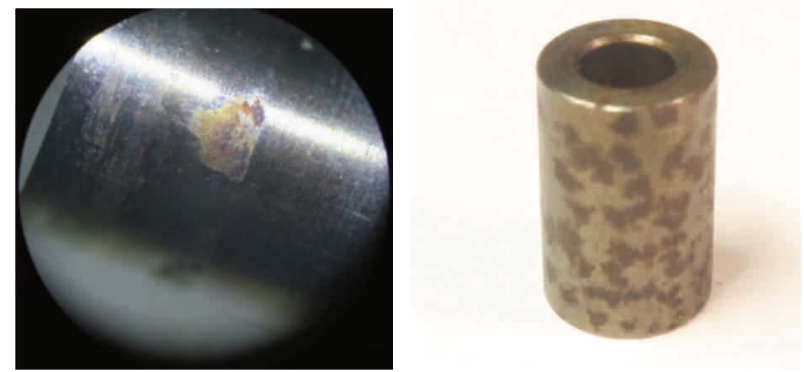

Fig. 19. Corrosion of the needle and the guiding sleeve

Figure 19 shows the corrosion damage of the upper part of the needle and the guiding sleeve. Corrosion has occurred in places that do not work with other parts, so it has no effect on the operation of the injector. On the other hand, further corrosion can lead to fuel contamination with corrosion products and damage other components.

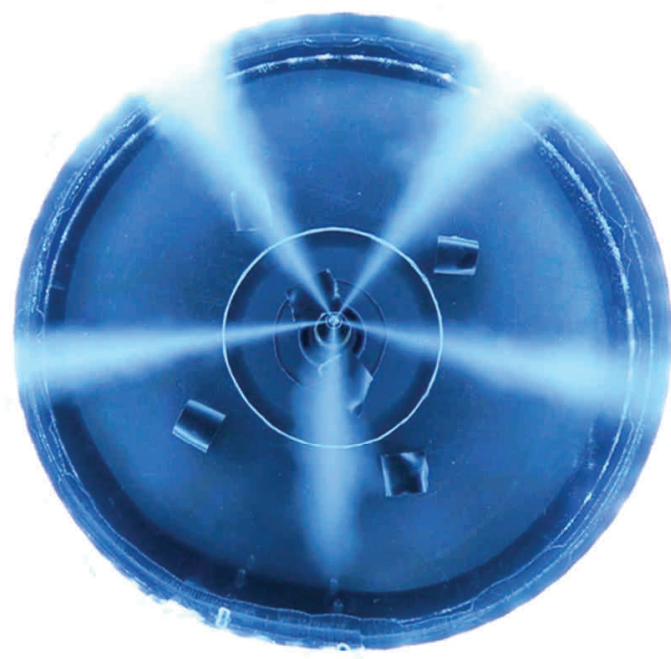

Fig. 20. Fuel spray pattern of a damaged injector

In addition, the spray pattern of the injector number 1 was documented (Fig. 20). The streams formed by the two upper holes are characterized by a larger cone angle than the others. Considering the amount of reflected light from these streams it can be inferred that they contained a higher injected fuel quantity. The spraying from the lower hole is 
severely opened from the beginning, while the sprayed droplets have not yet reached the wall of the visualization chamber. This means that spreading speed of the droplets flowing from the lower hole is smaller than those from the remaining holes. The reason for such phenomenon is because the flow through this channel is disturbed by the unevenness of its geometry, which may be due to internal sediments.

\section{Conclusions}

The standard 4-point injector test can detect most of the faults. Sometimes, however, it is required to have a full feature consisting of multi-point measurements, because in actual conditions the injector is operating and must perform at full pressure and opening times.

Comparative testing of test benches has shown that Bosch EPS is characterized by greater accuracy and precision of measurements, while STPiW has wider research capabilities and allows for arbitrary parameter setting during testing. Differences in the method of measuring the fuel dose and the course of the control pulses influence the divergence of the results obtained with these devices.

The visualization station, despite the simplicity and low cost of execution, allowed to observe and document the macro structure of the fuel spray jet. The instrument has made it possible to diagnose faults related to the quality of fuel spraying and to integrate it with the test bench in a laboratory of the Faculty of Mechanical Engineering, the device also has a didactic value. In spite of listed above wear an corosion demages the main injector problem are deposites [3]. The best method to limit the occurrence of the above phenomena is the application of effective detergent fuel addetives.

\section{Nomenclature}

VE pilot dosage

EM emission load dosage

LL idle dosage

VL full load dosage

\section{Bibliography}

[1] BOGUŚ, P., GRZESZCZYK, R., WRONA, A. et al. The possibility of applying wavelet analysis for diagnostics of the validity of injection process of diesel engine fuel injector
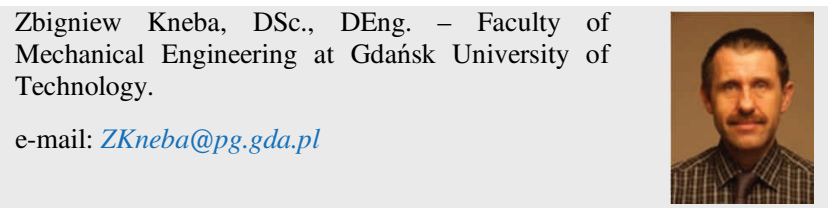

$$
\begin{aligned}
& \text { Paweł Straszak, BEng. } \\
& \text { e-mail: PawelStraszak@op.pl }
\end{aligned}
$$

based on selected parameters of the reactive cylinder vibration process. PTNSS-2015-3397.

[2] Instrukcja obsługi Bosch EPS 200.

[3] STĘPIEŃ Z. Investigation of injector deposits in modern diesel engines. Combustion Engines. 2016, 165(2), 9-20.

\author{
Klaudia Jakóbczyk, BEng. \\ e-mail: Jakobczyk.Klaudia@gmail.com
}


